\title{
xCT inhibitor sulfasalazine depletes paclitaxel-resistant tumor cells through ferroptosis in uterine serous carcinoma
}

\author{
AKIKO SUGIYAMA, TSUYOSHI OHTA, MIYUKI OBATA, KANAKO TAKAHASHI, \\ MANABU SEINO and SATORU NAGASE
}

Department of Obstetrics and Gynecology, Faculty of Medicine, Yamagata University, Yamagata 990-9585, Japan

Received October 16, 2019; Accepted May 27, 2020

DOI: 10.3892/ol.2020.11813

\begin{abstract}
Glutathione (GSH) is a primary antioxidant that protects cells against reactive oxygen species (ROS), and high levels of GSH promote cancer cell survival and resistance to chemotherapy. The glutamine transporter $\mathrm{xCT}$ is essential for the intracellular synthesis of GSH, whereby xCT determines the intracellular redox balance. However, whether $\mathrm{xCT}$ inhibition can overcome GSH-mediated resistance to chemotherapeutic agents in uterine serous carcinoma (USC) remains unclear. Thus, the present study investigated the effect of the $\mathrm{xCT}$ inhibitor, sulfasalazine (SAS) on cytotoxicity in paclitaxel-sensitive and -resistant USC cell lines. The molecular mechanism by which SAS induces ferroptotic cell death in paclitaxel-resistant cells was assessed. The results of the cytotoxicity assay demonstrated that SAS was more cytotoxic in paclitaxel-resistant cells compared with in -sensitive cells; however, paclitaxel cytotoxicity was not enhanced in either of the USC cell lines. Immunoblotting analysis and the cell death assays performed using ferroptosis inhibitors indicated that SAS-mediated cell death was induced through ferroptosis, and not apoptosis, in paclitaxel-resistant cells. Furthermore, ROS production was increased in paclitaxel-resistant but not in -sensitive cells, even at low SAS concentration, and JNK was activated, which is a downstream target in the Ras signaling pathway. Knockdown of JNK reversed the inhibitory effect of SAS on cell proliferation and cell death. The synthetic lethal interaction between ROS accumulation and Ras effector JNK activation may be critical for enhancing the sensitivity to ferroptotic cell death mediated by xCT inhibitor, SAS. Taken together, the results of the present study suggest
\end{abstract}

Correspondence to: Dr Tsuyoshi Ohta, Department of Obstetrics and Gynecology, Faculty of Medicine, Yamagata University, 2-2-2 Iidanishi, Yamagata 990-9585, Japan

E-mail: oota-t@med.id.yamagata-u.ac.jp

Abbreviations: GSH, glutathione; ROS, reactive oxygen species; USC, uterine serous carcinoma; SAS, sulfasalazine

Key words: SAS, USC, redox balance, ferroptosis, drug resistance that $\mathrm{xCT}$ inhibition may be an effective treatment for patients with recurrent paclitaxel-resistant USC.

\section{Introduction}

Uterine serous carcinoma (USC) accounts for $10 \%$ of all endometrial cancer worldwide; however, it contributes disproportionately to endometrial cancer mortality, whereby $40 \%$ of endometrial cancer-associated mortalities in 2016 were attributed to its high-risk histological subtype (1). Approximately $50 \%$ of patients are diagnosed with International Federation of Gynecology and Obstetrics (FIGO) stage 3-4, and the 5-year disease-specific survival rate for patients with advanced stage USC is reported to be $33 \%$ (2). Currently, the clinical management of advanced stage USC is based on primary cytoreductive surgery, followed by systematic chemotherapy (3). The adjuvant platinum/taxane chemotherapy decreases the recurrence risk and improves survival outcomes (3). However, most patients with advanced stage USC develop recurrent disease, which is resistant to chemotherapy and lethal in the majority of cases (4). Thus, it remains crucial to elucidate how USC becomes chemotherapy-resistant, and to develop novel treatment for recurrent USC, which are more effective compared with that in current therapies.

Prooxidant cancer therapies, including ionizing radiation and chemotherapy induce the production of reactive oxygen species (ROS) in cancer cells, and the addition of an additional oxidant stimulus to the constitutive oxidative stress in cancer cells causes the collapse of the antioxidant systems and thereby leads to cell death (5). Glutathione (GSH) is a primary antioxidant, which protects cells against ROS, and high levels of GSH have been associated with increasing cancer cell survival and resistance to chemotherapy in ovarian and prostate cancer cells $(6,7)$. Thus, the intracellular redox balance can determine the sensitivity of cancer cells to chemotherapeutic agents (8). Recently, metabolomics analyses demonstrated that GSH levels in a paclitaxel-resistant USC cell line were higher compared with that in a paclitaxel-sensitive cell line (9), which suggests that increased GSH levels are associated with the resistance to paclitaxel in USC. Intracellular GSH synthesis requires cystine uptake, and this involves the $\mathrm{xc}^{-}$system, a cystine-glutamate exchange transporter composed of xCT (the light-chain and active subunit) and F42hc (the heavy-chain subunit); $\mathrm{xCT}$ expression is essential for the cystine uptake 
necessary for intracellular GSH synthesis, and thus xCT can determine the intracellular redox balance $(10,11)$. Notably, $\mathrm{xCT}$ inhibition has been extensively demonstrated to overcome GSH-mediated resistance to chemotherapeutic agents in head and neck squamous carcinoma, lung cancer and colorectal cancer (12-14). However, whether XCT inhibition can overcome paclitaxel resistance in USC remains unknown.

Sulfasalazine (SAS), an anti-inflammatory drug, which is clinically used for treating bowel disease and rheumatoid arthritis (15), is a specific inhibitor of xCT-mediated cystine transporter $(10,16)$. SAS can scavenge ROS, as an anti-inflammatory drug (17), inhibit leukocyte motility and interleukin (IL)-1 and IL-2 production (18), and inhibit nuclear factor $\kappa \mathrm{B}$ (NFKB) (19). SAS has also been reported to effectively induce GSH depletion (90\%) and arrest growth, and to enhance sensitivity to chemotherapeutic agents in pancreatic, prostate and mammary cancer (20-23). As SAS inhibits a cystine-glutamate transporter, it can promote ferroptosis, a non-apoptotic form of cell death $(24,25)$. This lethal process is defined by iron-dependent accumulation of lipid ROS $(24,25)$, and cancer cells exhibiting high levels of Ras activity or p53 expression may be sensitized to this process (24).

The present study aimed to investigate whether the $\mathrm{xCT}$ inhibitor, SAS, induced cytotoxicity and cell death using cytotoxicity and cell death assays in the paclitaxel-sensitive USPC1 and -resistant PTX1 cell lines. Furthermore, the molecular mechanism by which SAS induces cell death in cancer cells was assessed.

\section{Materials and methods}

Cell culture. Human uterine serous papillary carcinoma-1 (USPC1) cell lines were established by Dr Santin at the Department of Obstetrics and Gynecology, Division of Gynecologic Oncology, Yale University (New Haven, United States) (26), from patients who experienced rapid tumor progression during adjuvant chemotherapy following primary surgery. The paclitaxel-resistant cell line,PTX1 was established from paclitaxel-sensitive USPC1 cells. To generate paclitaxel-resistant cells, USPC1 cells were continuously exposed to doses of paclitaxel half-maximal inhibitory concentration (IC50) values. Cells were split every 2 weeks and cultured in RPMI-1640 (Thermo Fisher Scientific, Inc.) medium supplemented with $10 \%$ FBS (Cytiva), an antibiotic-antimycotic mixture $(100 \mathrm{U} / \mathrm{ml}$ penicillin, $100 \mu \mathrm{g} / \mathrm{ml}$ streptomycin and $250 \mathrm{ng} / \mathrm{ml}$ amphotericin B; Thermo Fisher Scientific, Inc.) and GlutaMax supplement (2 mM L-glutamine; Thermo Fisher Scientific, Inc.) at $37^{\circ} \mathrm{C}$ in a humidified atmosphere with $5 \%$ $\mathrm{CO}_{2}$, with recalculated paclitaxel IC50 values for 3 months (9).

UCPC1 and PTX1 cells were provided by Dr Yaegashi at the Department of Gynecology and Obstetrics, Tohoku University Graduate School of Medicine (Sendai, Japan). Cells were cultured in RPMI-1640 medium supplemented with $10 \%$ FBS, an antibiotic-antimycotic mixture $(100 \mathrm{U} / \mathrm{ml}$ penicillin, $100 \mu \mathrm{g} / \mathrm{ml}$ streptomycin and $250 \mathrm{ng} / \mathrm{ml}$ amphotericin B) and GlutaMax supplement (2 $\mathrm{mM}$ L-glutamine), at $37^{\circ} \mathrm{C}$ in a humidified atmosphere of $95 \%$ air and $5 \% \mathrm{CO}_{2}$.

The human ovarian cancer SKOV3 cell line was obtained from the American Type Culture Collection. Cells were cultured in M199:105 (Sigma-Aldrich; Merck KGaA) medium with $10 \%$ FBS and 1\% penicillin-streptomycin (Sigma-Aldrich; Merck $\mathrm{KGaA}$ ) at $37^{\circ} \mathrm{C}$ in a humidified atmosphere with $5 \% \mathrm{CO}_{2}$.

Antibodies and reagents. The following antibodies were purchased against: xCT (1:1,000; cat. no. ab37185; Abcam), cleaved-PARP (1:1,000; cat. no. 9541; Cell Signaling Technology, Inc.), Akt (1:1,000; cat. no. 9272; Cell Signaling Technology, Inc.), phosphorylated (p)-Akt (1:1,000; cat. no. 4058; Cell Signaling Technology, Inc.), p44/42 MAPK (Erk1/2; 1:1,000; cat. no. 4695; Cell Signaling Technology, Inc.), p-p44/42 MAPK (1:1,000; cat. no. 9106; Cell Signaling Technology, Inc.), p-SAPK/JNK (1:1,000; cat. no. 9251; Cell Signaling Technology, Inc.), JNK2 (1:200; cat. no. sc7345; Santa Cruz Biotechnology, Inc.) and $\beta$-actin $(1: 1,000$; cat. no. A2228; Sigma-Aldrich; Merck KGaA).

The following reagents were purchased and dissolved in DMSO or distilled water to prepare the stock solutions: $100 \mathrm{mM}$ SAS, $10 \mathrm{mM}$ 2',7'-dichlorofluorescin diacetate (DCFH-DA) and $10 \mathrm{mM}$ ferrostatin-1 (all dissolved in DMSO and from Sigma-Aldrich; Merck KGaA). A total of $10 \mathrm{mM}$ deferoxamine mesylate (DFO) (cat. no. ab120727; Abcam) was dissolved in water and $10 \mathrm{mM}$ Z-VAD-FMK (Peptide Institute, Inc.) in DMSO.

Cytotoxicity and cell death assays. Following treatment at $37^{\circ} \mathrm{C}$ in a humidified atmosphere with $5 \% \mathrm{CO}_{2}$ with paclitaxel $(0,0.1,1,10,50$ or $100 \mathrm{nM})$ for $72 \mathrm{~h}$, or treatment with SAS $(100$ or $200 \mu \mathrm{M})$ and paclitaxel $(0,0.1,1,10,100$ or $1,000 \mathrm{nM}$ ) for $72 \mathrm{~h}$ in USPC1 and PTX1 cells, or treatment with ferrostatin-1 $(1 \mu \mathrm{M})$ or Z-VAD-FMK $(100 \mu \mathrm{M})$ for $1 \mathrm{~h}$ and subsequent treatment with SAS $(0,200,400,600,800$, $1,000 \mu \mathrm{M})$ for $72 \mathrm{~h}$ in PTX1 cells, or treatment with DFO $(1 \mu \mathrm{M})$ for $1 \mathrm{~h}$ and subsequent treatment with SAS $(400 \mu \mathrm{M})$ for $48 \mathrm{~h}$ in PTX1 cells, cell viability was assessed using the tetrazolium compound, MTS, at $37^{\circ} \mathrm{C}$ for $1.5 \mathrm{~h}$ according to the manufacturer's protocol (Promega Corporation). Following the MTS assay, samples were incubated with CellTiter $96^{\circledR}$ AQueous One Solution reagent (Promega Corporation) for $90 \mathrm{~min}$ at $37^{\circ} \mathrm{C}$ and cell viability was subsequently analyzed at $490 \mathrm{~nm}$ using a Model 680 Microplate Reader ${ }^{\circledR}$ (Bio-Rad Laboratories, Inc.). Cell viability was calculated from the ratio of cells treated with each of the drugs to that of untreated cells, set as 1 (mean $\pm \mathrm{SD} ; \mathrm{n}=8)$. Untreated cells were used as a control.

The cell death assay was conducted as previously described (27). Following treatment at $37^{\circ} \mathrm{C}$ in a humidified atmosphere with $5 \% \mathrm{CO}_{2}$ with SAS $(200 \mu \mathrm{M})$ for $24 \mathrm{~h}$ in USPC1 and PTX1 cells, or treatment with ferrostatin-1 $(1 \mu \mathrm{M})$ for $1 \mathrm{~h}$ and subsequent treatment with SAS $(200 \mu \mathrm{M})$ for $24 \mathrm{~h}$ in PTX1 cells, cells were incubated with $1 \mu \mathrm{g} / \mathrm{ml}$ propidium iodide (PI; Invitrogen; Thermo Fisher Scientific, Inc.) and $10 \mu \mathrm{g} / \mathrm{ml}$ Hoechst 33342 (Invitrogen; Thermo Fisher Scientific, Inc.) at $37^{\circ} \mathrm{C}$ for $10 \mathrm{~min}$ to stain dead cells and the cell nuclei, respectively. Subsequently, the numbers of PI- and Hoechst-positive cells were scored manually under a fluorescence microscope (CKX41; Olympus Corporation; magnification, x100) in five fields per well, and the rate of PI-positive cells (dead cells) against Hoechst-positive cells (total cells) was determined. All the experiments were carried out in quadruplicate. 
GSH and ROS measurements. To confirm the increase of GSH levels in a cell number-dependent manner, cells were plated a density of $1,000,3,000$ or 5,000 cells/well in 96-well plates. After $24 \mathrm{~h}, \mathrm{GSH}$ levels were measured using the GSH-GloTM Glutathione assay according to the manufacturer's protocol (Promega Corporation) in USPC1 and PTX1 cells. GSH levels were measured in both cells treated with SAS $(400 \mu \mathrm{M})$ or paclitaxel $(10 \mu \mathrm{M})$ at $37^{\circ} \mathrm{C}$ in a humidified atmosphere with $5 \% \mathrm{CO}_{2}$ for $24 \mathrm{~h}$ using the GSH-GloTM Glutathione assay. GSH levels were calculated from the ratio of cells treated with SAS or paclitaxel to that of untreated USPC1 cells set as 1 (mean $\pm \mathrm{SD} ; \mathrm{n}=8$ ). For ROS measurement, cells were treated with vehicle, SAS $(200 \mu \mathrm{M})$, paclitaxel $(10 \mathrm{nM})$ or SAS + paclitaxel at $37^{\circ} \mathrm{C}$ in a humidified atmosphere with $5 \% \mathrm{CO}_{2}$ for $24 \mathrm{~h}$. ROS levels were measured following treatment of cells with $10 \mu \mathrm{M}$ DCFH-DA for $30 \mathrm{~min}$ at $37^{\circ} \mathrm{C}$. Cells were protected from light during the respective procedures. Cells exhibiting a signal for DCFH-DA above the gate established using the isotype control treated without DCFH-DA were deemed ROS-positive. These cells were subsequently used in FACS analysis to quantify the intensity of DCF fluorescence, using a FACSCantoTM II flow cytometer (BD Biosciences). All the experiments were carried out in quadruplicate.

Western blot analysis. Cells were washed twice with cold PBS and lysed using RIPA lysis buffer (50 mM Tris- $\mathrm{HCl}$, pH 7.5, $150 \mathrm{mM} \mathrm{NaCl}, 0.1 \%$ SDS, $1 \%$ Triton X-100, $1 \mathrm{mM}$ phenylmethylsulfonyl fluoride). Protein concentration was determined using a BioPhotometer ${ }^{\circledR}$ (Eppendorf, Hamburg, Germany). Cell lysates containing equal amounts of protein $(25 \mu \mathrm{g} / \mathrm{well})$ were separated using 5\% SDS-PAGE and transferred onto nitrocellulose membranes. Blocking was performed using $5 \%$ skimmed milk powder or $3 \%$ bovine serum albumin (Sigma-Aldrich; Merck KGaA) in 1X TBS at room temperature for $1 \mathrm{~h}$. The membrane was sequentially probed with the aforementioned primary antibodies overnight at $4^{\circ} \mathrm{C}$, and then with an appropriate horseradish peroxidase (HRP)-conjugated secondary antibody at room temperature for $1 \mathrm{~h}$, according to the manufacturer's protocols. The secondary antibodies used were: Mouse IgG HRP Linked Whole Ab (1:5,000; cat. no. NA931-1ML) and Rabbit IgG HRP Linked Whole Ab (1:5,000; cat. no. NA934-1ML), both purchased from Cytiva. Immunoreactive bands were visualized using Amersham ${ }^{\mathrm{TM}}$ ECLTM prime western blotting detection reagent (Cytiva). SKOV3, USPC1, and PTX1 cell were cultured at $37^{\circ} \mathrm{C}$ in a humidified atmosphere with $5 \%$ $\mathrm{CO}_{2}$ for $24 \mathrm{~h}$, and the cell lysate were probed for anti-xCT antibody using western blot analysis. USPC1 and PTX1 cells were treated with vehicle, SAS $(200 \mu \mathrm{M})$, paclitaxel $(10 \mathrm{nM})$ or SAS + paclitaxel at $37^{\circ} \mathrm{C}$ in a humidified atmosphere with $5 \% \mathrm{CO}_{2}$ for $24 \mathrm{~h}$, and the cell lysates were probed for anti-cleaved-PARP antibody using western blot analysis. USPC1 and PTX1 cells were cultured at $37^{\circ} \mathrm{C}$ in a humidified atmosphere with $5 \% \mathrm{CO}_{2}$ for $24 \mathrm{~h}$, and the cell lysates were probed for p-AKT, AKT, p-Erk, Erk, p-JNK or JNK antibody using western blot analysis. PTX1 cells transfected with siRNAs against JNK or with a control siRNA were cultured at $37^{\circ} \mathrm{C}$ in a humidified atmosphere with $5 \% \mathrm{CO}_{2}$ for $24 \mathrm{~h}$, and the cell lysates were probed for anti-p-JNK or anti-JNK antibodies using western blot analysis.
Reverse transcription (RT) PCR. Total RNA was extracted from cells using the RNeasy ${ }^{\circledR}$ Mini kit, and cDNA was synthesized from $1 \mu \mathrm{g}$ RNA using the QuantiTect ${ }^{\circledR}$ Reverse Transcription kit (both from Qiagen K.K.). RT PCR was performed on a T100TM thermal cycler (Bio-Rad Laboratories, Inc.). The following primer sequences were used: CD44 forward, 5'-TCCCAGACGAAGACAGTCCCTGGAT-3' and reverse, 5'-CACTGGGGTGGAATGTGTCTTGGTC-3'; and GAPDH forward, 5'-ACCACAGTCCATGCCATCAC-3' and reverse, 5'-TCCACCCTGTTGCTGTA-3'. The thermocycling conditions for $\mathrm{CD} 44$ amplification involved an initial denaturation step at $95^{\circ} \mathrm{C}$ for $3 \mathrm{~min}$, followed by 34 cycles of denaturation at $95^{\circ} \mathrm{C}$ for $30 \mathrm{sec}$, annealing at $60^{\circ} \mathrm{C}$ for $30 \mathrm{sec}$ and extension at $72^{\circ} \mathrm{C}$ for $1 \mathrm{~min}$, with a final extension step at $72^{\circ} \mathrm{C}$ for $5 \mathrm{~min}$. The thermocycling conditions for GAPDH involved an initial denaturation step at $95^{\circ} \mathrm{C}$ for $3 \mathrm{~min}$, followed by 29 cycles of denaturation at $95^{\circ} \mathrm{C}$ for $30 \mathrm{sec}$, annealing at $55^{\circ} \mathrm{C}$ for $30 \mathrm{sec}$ and extension at $72^{\circ} \mathrm{C}$ for $1 \mathrm{~min}$, with a final extension step at $72^{\circ} \mathrm{C}$ for $5 \mathrm{~min}$. PCR products were electrophoresed on $2 \%$ agarose gels containing ethidium bromide and photographed. The exons 1-5 and 16-20 that encode the constant part of CD44 are included in all CD44 isoforms (28). Exons 6-15 that encode the variant exons v1-v10 are either completely excluded, as in CD44s, or are included in various combinations within the CD44 ectodomain, giving rise to the CD44 variant isoforms (CD44v) (28). CD44v8-10 contains the variant exons 8-10 and has more bases than CD44s. The primer for CD44 can detect both CD44s (83 bp) and CD44v8-10 (479 bp).

Gene silencing by small interfering (si)RNA. siRNAs against human JNK2 (cat. no. VHS40729) as well as Medium GC Duplex \#2 of Stealth RNAi ${ }^{\mathrm{TM}}$ siRNA Negative Control Duplexes were purchased from Invitrogen (Thermo Fisher Scientific, Inc.). Transfection with siRNAs (100 nmol/l) was performed using Lipofectamine ${ }^{\circledR}$ RNAiMAX $^{\text {TM }}$ reagent (Thermo Fisher Scientific, Inc.), according to the manufacturer's protocol. After $4 \mathrm{~h}$, the transfection medium was removed and replaced with culture medium. The transfected cells were cultured at $37^{\circ} \mathrm{C}$ in a humidified atmosphere with $5 \% \mathrm{CO}_{2}$ for $24 \mathrm{~h}$, and then were used for western blot analysis, MTS assay and cell death assay. All of the experiments were carried out in quadruplicate.

Subcutaneous xenograft model and treatment in vivo. The procedures involving animals used in the present study were approved by the Animal Care Committee of Yamagata University (approval no. 31009) in accordance with institutional and Japanese government guidelines for animal experiments. The total number of mice used was 14 in all experiments. The mean weight of the mice at the start was $19.4 \pm 0.87 \mathrm{~g}$. Housing conditions were as follows: Temperature was $37^{\circ} \mathrm{C}$, humidity was $30-40 \%$, light/dark cycle was every $12 \mathrm{~h}$, food and water were sterilized and available ad libitum. To generate the subcutaneous xenograft model, USPC1 $\left(5 \times 10^{6}\right.$ cells) or PTX1 (5x $10^{6}$ cells) were suspended in $200 \mu 1$ of PBS following determination of cellular viability and injected into the subcutaneous tissue of 6-week-old female Crj:SHO-Prkde ${ }^{\text {scid }} \mathrm{Hr}^{\text {hr }}$ hairless SCID mice ( $\mathrm{n}=2)$ (Charles River Laboratories Inc.). Tumor formation was visually confirmed in mice inoculated with USPC1 cells, but not in those inoculated with PTX1 cells, 
thus the animal study was performed using USPC1 cells. The recipient mice were monitored for general health status and presence of subcutaneous tumors once a week. Tumor volume was determined by measuring tumor diameters (measurement of 2 perpendicular axes of the tumors) and calculated as $1 / 2 \mathrm{x}$ (larger diameter)x(smaller diameter) ${ }^{2}$. A total of two weeks following inoculation, one group of mice $(n=6)$ was administered with oral PBS five times a week (Monday to Friday) for eight weeks. A second group of mice $(n=6)$ was administered with SAS suspension $(250 \mathrm{mg} / \mathrm{kg}$ ) orally five times a week (Monday to Friday) for eight weeks. A total of nine weeks following initialization of treatment, mice were euthanized with $100 \% \mathrm{CO}_{2}$ at a flow rate of $20 \%$ of the chamber volume per minute, which was used for 5 min to reach $100 \% \mathrm{CO}_{2}$ in the chamber. Mice remained in $100 \% \mathrm{CO}_{2}$ for $\geq 10 \mathrm{~min}$ to ensure that they were dead.

Statistical analysis. Statistical analysis was performed using GraphPad Prism software (version 5.0; GraphPad Software, Inc.). Data are presented as the mean \pm SD $(n=4)$. Unpaired Student's t-test was used to compare differences between two groups, while one-way or two-way ANOVA, followed by Bonferroni post hoc test were used to compare differences between multiple groups. $\mathrm{P}<0.05$ was considered to indicate a statistically significant difference.

\section{Results}

Effects of SAS on the proliferation of paclitaxel-sensitive and -resistant USC cells. xCT expression in the USC cell lines was assessed and the SKOV3 cells were used as the positive control, as they express xCT. Western blot analysis demonstrated that $\mathrm{xCT}$ was highly expressed in paclitaxel-sensitive USPC1 and paclitaxel-resistant PTX1 cells (Fig. 1A). CD44, a major extracellular matrix adhesion molecule, exists as several isoforms, including CD44v, and is generated through mRNA splicing (29). CD44v can stabilize xCT and control the intracellular redox status in an $\mathrm{xCT}$ activity-dependent manner (30,31). RT-PCR analysis revealed that CD44s and CD44v8-10 were expressed in USPC1 cells, but not in PTX1 cells (Fig. S1).

Paclitaxel sensitivity in USPC1 and PTX1 cells was subsequently investigated using the MTS assay. Cells were treated with different concentrations of paclitaxel for $72 \mathrm{~h}$, and cell viability was significantly inhibited in paclitaxel-sensitive USPC1 cells but not paclitaxel-resistant PTX1 cells, compared with that in the untreated control cells when $>50 \mathrm{nM}$ paclitaxel was used (Fig. 1B).

To determine the effect of SAS on USC cell viability, cells were treated with different concentrations of SAS for $72 \mathrm{~h}$. SAS significantly inhibited cell viability in PTX1 cells, in a dose-dependent manner compared with that in the untreated control cells, and significantly decreased cell viability in USPC1 cells when $>600 \mu \mathrm{M}$ SAS was used (Fig. 1C).

The effect of SAS on paclitaxel cytotoxicity was also assessed by treating cells with different concentrations of paclitaxel alone or in combination with SAS for $72 \mathrm{~h}$. In USPC 1 cells, combination of paclitaxel with $200 \mu \mathrm{M}$ SAS had no significant effect on cell proliferation compared with that in cells treated with paclitaxel alone (Fig. 1D; left panel). As
$200 \mu \mathrm{M}$ SAS decreased cell viability by $60 \%$ in PTX1 cells (Fig. 1C) and the cytotoxic effect of $200 \mu \mathrm{M}$ SAS was too strong to detect the effect of combination with SAS and paclitaxel, $100 \mu \mathrm{M}$ SAS was used in combination with different concentrations of paclitaxel in PTX1 cells, and the results showed a significant decrease in cell viability at each concentration of paclitaxel compared with that in cells treated with paclitaxel alone (Fig. 1D; right panel). These results indicated the effect of SAS, and SAS did not enhance the efficacy of paclitaxel. Taken together, these results suggest that SAS inhibited cell proliferation more effectively in paclitaxel-resistant compared with that in -sensitive cells; however, SAS failed to enhance paclitaxel cytotoxicity in either of the USC cell lines.

GSH levels and ROS accumulation in USC cell lines treated with SAS and/or paclitaxel. To verify the inhibitory effect of SAS on xCT-mediated cystine transport, GSH levels and ROS accumulation in USC cells were assessed, both prior to and following treatment with SAS or paclitaxel. Consistent with our previous study (9), the results demonstrated that intracellular GSH levels were significantly higher in PTX1 cells compared with that in USPC1 cells (Fig. 2A). Furthermore, treatment with $400 \mu \mathrm{M}$ SAS for $24 \mathrm{~h}$ significantly decreased the intracellular GSH contents in both cell lines (Fig. 2B), whereas treatment with $10 \mathrm{nM}$ paclitaxel for $24 \mathrm{~h}$ had no effect on the intracellular GSH content in either cell line (Fig. 2C).

The intracellular ROS levels in USC cells treated with SAS and/or paclitaxel were assessed using FACS analysis and DCFH-DA. Since $200 \mu \mathrm{M}$ SAS exhibited a marked difference on cytotoxicity between USPC1 and PTX1 cells, the intracellular ROS levels were analyzed in both cells treated with $200 \mu \mathrm{M}$ SAS. Treatment of USPC1 cells with $200 \mu \mathrm{M}$ SAS for $24 \mathrm{~h}$ had no effect on ROS levels compared with that in the vehicle-treated control, whereas treatment with either $10 \mathrm{nM}$ paclitaxel or combination of paclitaxel with $200 \mu \mathrm{M}$ SAS markedly increased ROS accumulation compared with that in the vehicle-treated control (Fig. 2D; upper panels). Furthermore, treatment with SAS increased ROS accumulation by 12 -fold in PTX1 cells compared with that in the vehicle-treated control cells, whereas combination treatment of paclitaxel with SAS increased ROS accumulation by 14-fold compared with that in the vehicle-treated control in PTX1 cells (Fig. 2D; lower panels). However, combination treatment of paclitaxel with SAS failed to markedly increase ROS accumulation in PTX1 cells compared with that in cells treated with SAS alone. Collectively, these results indicate that SAS-mediated GSH depletion markedly affected ROS accumulation in paclitaxel- resistant cells, but not in -sensitive cells.

SAS kills USC cells by inducing a form of non-apoptotic cell death. The cell death assay was performed to determine whether SAS induces USC cell death. PI staining revealed that $200 \mu \mathrm{M}$ SAS significantly induced cell death in PTX1 cells but not in USPC1 cells (Fig. 3A). SAS has been reported to induce cell death and inhibit tumor growth through apoptosis in colorectal cancer (14), and head and neck squamous cell carcinoma (12). Thus, the expression levels of cleaved-PARP, an apoptotic maker (32) were investigated. Western blot analysis demonstrated that treatment with SAS alone 
A

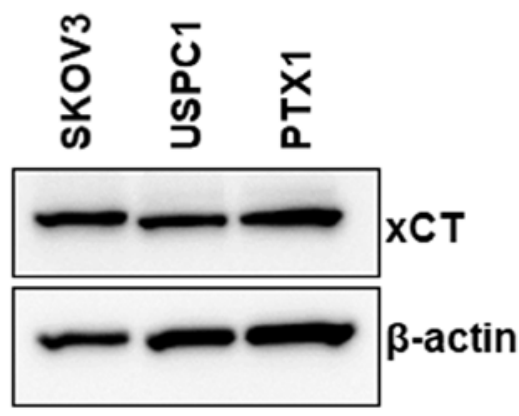

B

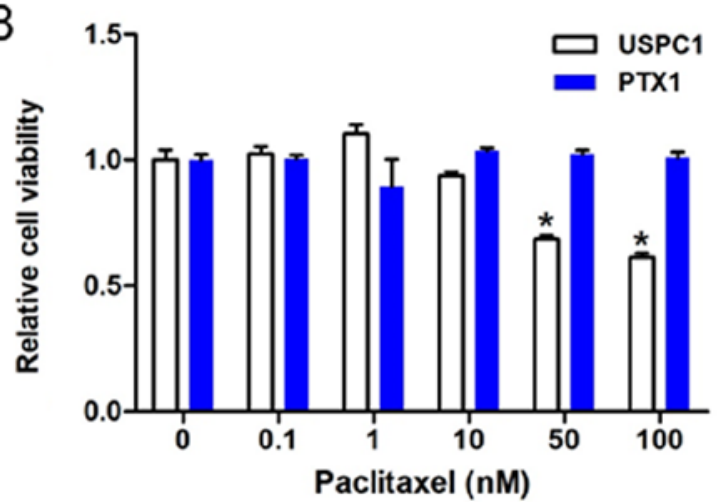

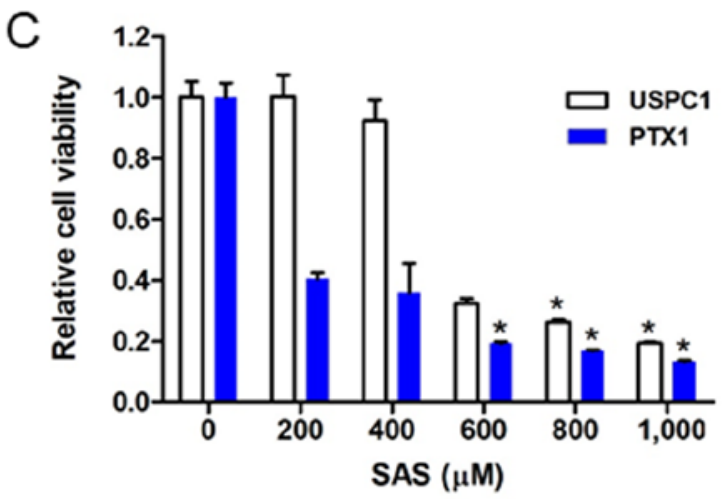
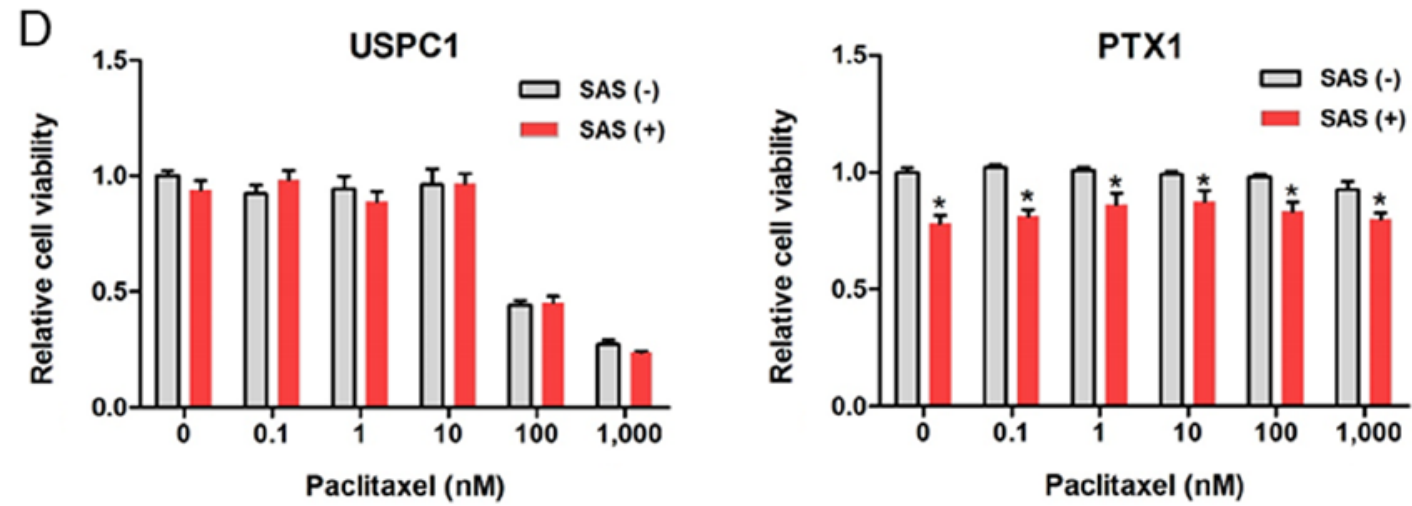

Figure 1. SAS inhibits cell proliferation in uterine serous carcinoma cell lines. (A) Western blot analysis was performed to determine the xCT expression levels in USPC1, PTX1 and SKOV3 cells. $\beta$-actin was used as the internal control. USPC1 and PTX1 cells were treated with different concentrations of (B) paclitaxel, (C) SAS and (D) paclitaxel alone, or in combination with $200 \mu \mathrm{M}$ or $100 \mu \mathrm{M} \mathrm{SAS}$, respectively. Cell viability was assessed after $72 \mathrm{~h}$ using the MTS assay. Cell viability was calculated from the ratio of the absorbance of cells treated with each of the drugs to that of untreated cells set as 1 (mean \pm SD; $n=8$ ). Data are presented as the mean \pm SD. " $\mathrm{P}<0.05$ vs. untreated cells. SAS, sulfasalazine; USPC1, uterine serous papillary carcinoma-1; -, without; +, with.

increased the levels of cleaved-PARP in USPC1 but not in PTX1 cells, compared with that in the vehicle-treated control (Fig. 3B). Furthermore, combination treatment of paclitaxel with SAS decreased the levels of cleaved-PARP in both cell lines compared with that in cells treated with paclitaxel alone (Fig. 3B). These results were in contrast to the cell death and cytotoxicity assays, suggesting that SAS induces cell death and cytotoxicity through a non-apoptotic pathway in USC cells.

SAS inhibits cell proliferation and induces cell death through ferroptosis in paclitaxel-resistant USC cells. The potential molecular mechanisms by which SAS induces cell death in paclitaxel-resistant USC cells were investigated. SAS has been reported to induce ferroptotic cell death in glioma cells (33).
Thus, the present study investigated whether the ferroptosis inhibitor, ferrostatin-1, reverses the effects of SAS on inducing cytotoxicity and cell death in PTX1 cells. Briefly, PTX1 cells were treated with SAS alone or a combination of ferrostatin-1 with SAS for $72 \mathrm{~h}$. The results demonstrated that combination treatment of ferrostatin-1 with SAS significantly increased cell viability compared with that in cells treated with SAS alone (Fig. 4A). Furthermore, PI staining demonstrated that combination treatment of ferrostatin-1 with SAS reversed SAS-induced cell death (Fig. 4B). Cell viability significantly increased following combination treatment of the iron chelator, DFO with SAS compared with that in cells treated with SAS alone (Fig. 4C). To further confirm that SAS-induced cell death occurred through ferroptosis and not apoptosis, 
A

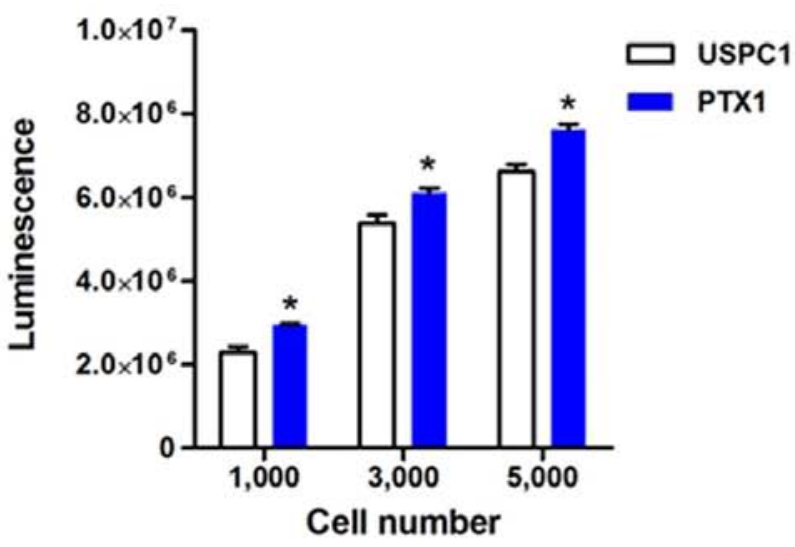

B
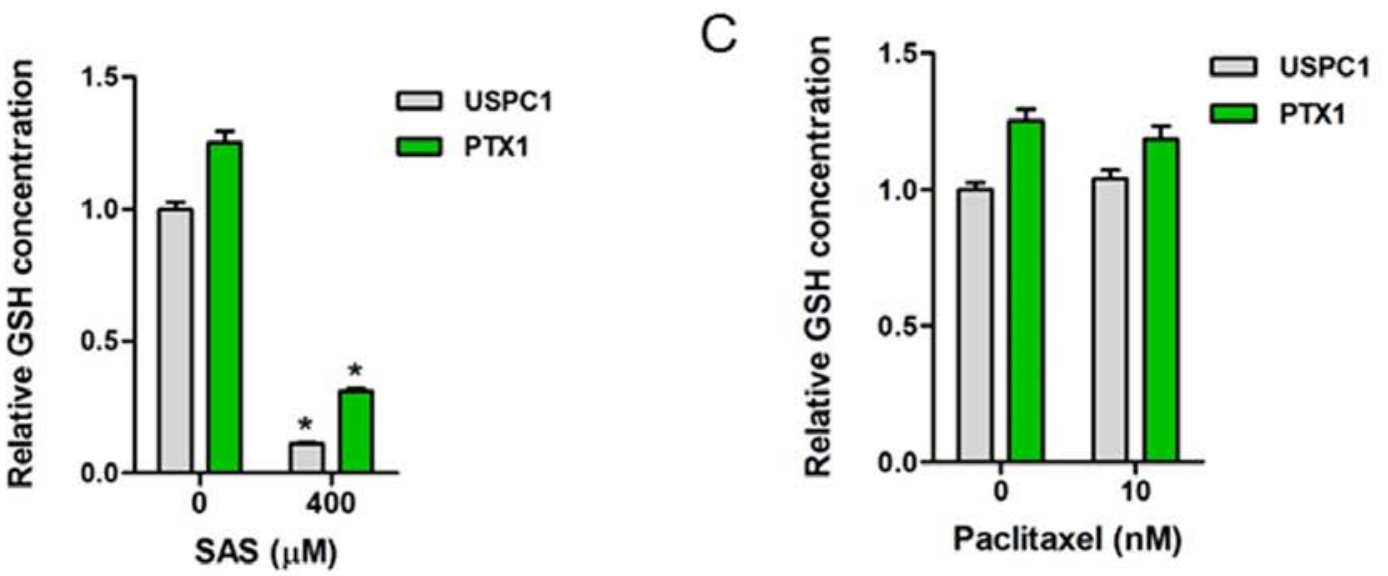

D

USPC1
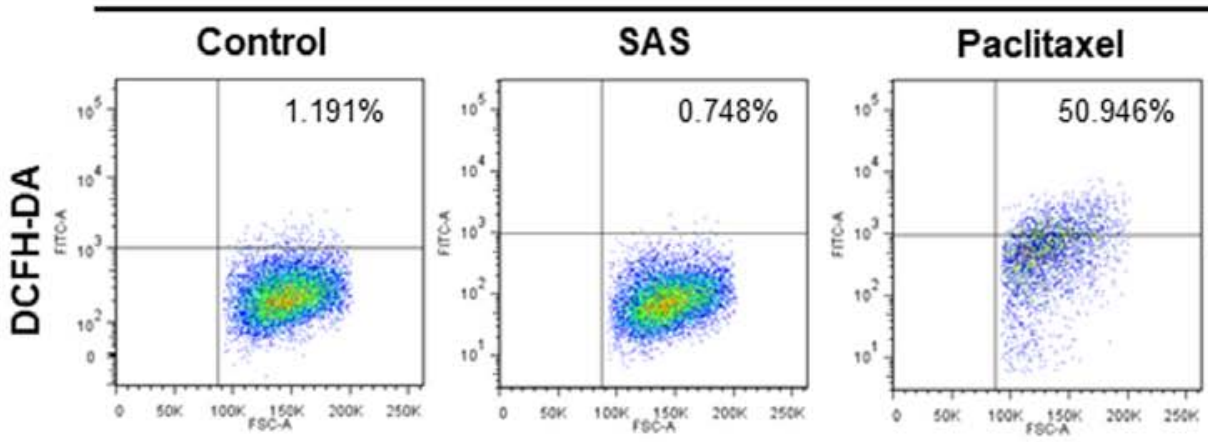

SAS+Paclitaxel

PTX1
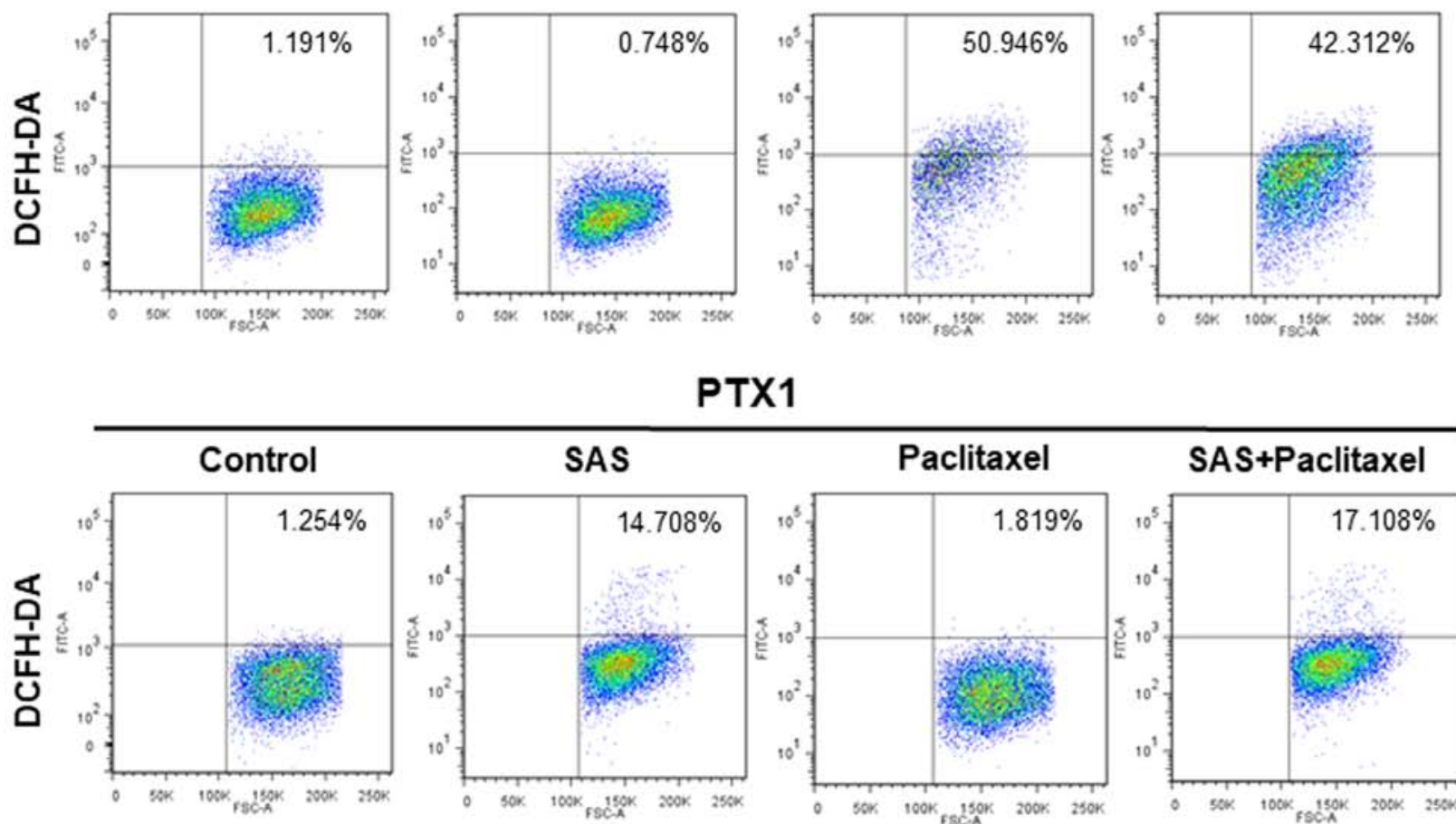

Figure 2. GSH levels and ROS accumulation in uterine serous carcinoma cell lines. (A) GSH levels were determined in USPC1 and PTX1 cells. Data are presented as the mean \pm SD. "P $<0.05$ vs. USPC1. Cellular GSH concentrations in USPC1 and PTX1 cells were measured before and after treatment with (B) SAS $(400 \mu \mathrm{M})$ or $(\mathrm{C})$ paclitaxel $(10 \mathrm{nM})$ for $24 \mathrm{~h}$. GSH levels were calculated from the ratio of cells treated with SAS or paclitaxel to that of untreated USPC1 cells set as 1 (mean $\pm \mathrm{SD} ; \mathrm{n}=8$ ). Data are presented as the mean $\pm \mathrm{SD}$. ${ }^{*} \mathrm{P}<0.05$ vs. untreated cells. (D) USPC1 and PTX1 cells were treated with SAS $(200 \mu \mathrm{M})$ and/or paclitaxel $(10 \mathrm{nM})$ for $24 \mathrm{~h}$, and flow cytometric analysis was performed to determine the intracellular ROS levels, following staining with DCFH-DA. GSH, glutathione; ROS, reactive oxygen species; SAS, sulfasalazine; DCFH-DA, 2',7'-dichlorofluorescin diacetate; USPC1, uterine serous papillary carcinoma-1. 


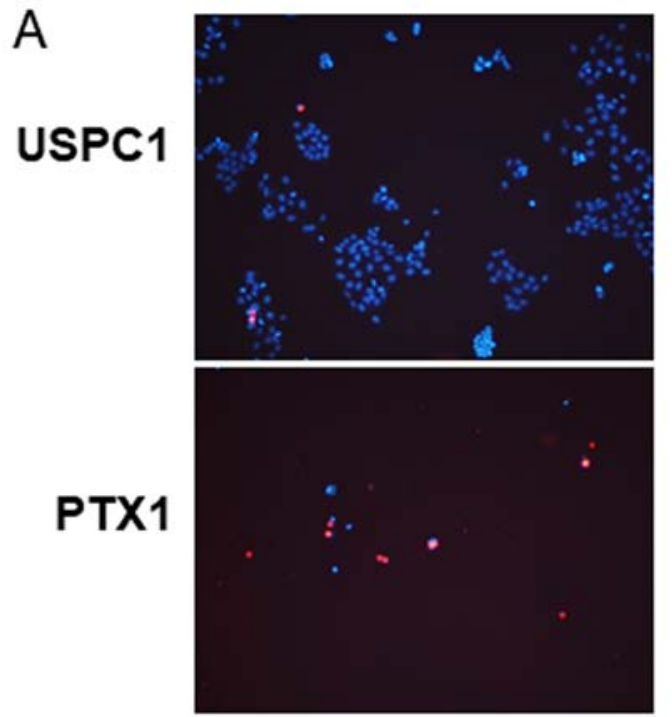

SAS $(200 \mu \mathrm{M})$
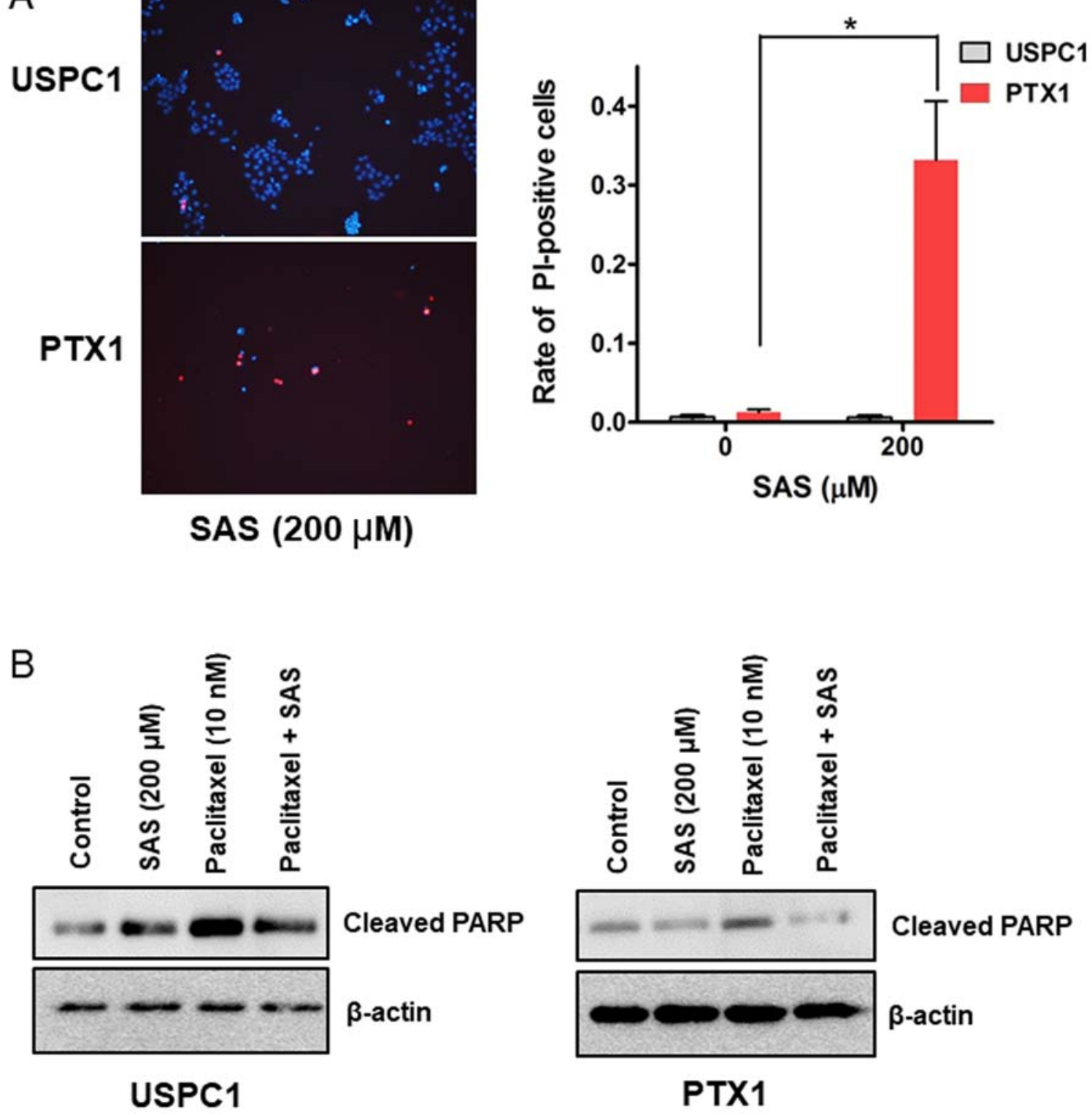

Figure 3. SAS induces cell death and cleaved-PARP expression in uterine serous carcinoma cells. (A) USPC1 and PTX1 cells were treated with SAS (200 $\mu$ M) for $24 \mathrm{~h}$ and the cell death assay was performed using PI and Hoechst nuclear staining. Left panel: Representative PI and Hoechst fluorescence images, right panel: Rate of PI-positive cells. Data are presented as the mean \pm SD. ${ }^{*} \mathrm{P}<0.05$. (B) USPC1 and PTX1 cells were treated with SAS (200 $\mu \mathrm{M}$ ) and/or paclitaxel $(10 \mathrm{nM})$ for $24 \mathrm{~h}$, and the cell lysates were probed for anti-cleaved-PARP antibody using western blot analysis. $\beta$-actin was used as the internal control. SAS, sulfasalazine; PI, propidium iodide.

cells were co-treated with SAS and the apoptotic inhibitor, Z-VAD-FMK (34). The results indicated that Z-VAD-FMK had no effect on the inhibitory effect of SAS on cell proliferation (Fig. 4D). Taken together, these results suggest that ferroptosis plays a key role in SAS-induced cell proliferation inhibition and cell death in paclitaxel-resistant USC cells.

Knockdown of JNK results in loss of SAS-induced cell proliferation inhibition and cell death. Ferroptosis was originally characterized in a previous study investigating compounds which are selectively lethal to RAS-mutant tumor cells (24). Thus, it was hypothesized that the effect of SAS on cell death depends on Ras activity in USC cells. The present study investigated the expression and activation of the Ras effectors, AKT, Erk and JNK before treatment with SAS in USPC1 and
PTX1 cells. Western blot analysis demonstrated no differences in the levels of phosphorylated AKT and Erk levels between USPC1 and PTX1 cells (Fig. 5A and B), whereas phosphorylated JNK levels were higher in PTX1 cells compared with that in USPC1 cells (Fig. 5C). To verify the association between SAS and the JNK signaling pathway, the effect of JNK knockdown on SAS-induced cell proliferation inhibition and cell death was investigated. PTX1 cells were transiently transfected with siRNA against JNK to effectively inhibit JNK activity. Western blot analysis demonstrated that transfection with siRNA-JNK decreased the expression levels of phosphorylated JNK and total JNK compared with that in the control cells (Fig. 5D). Furthermore, knockdown of JNK reversed SAS-induced cell proliferation inhibition (Fig. 5E) and cell death (Fig. 5F). Taken together, these results 
A

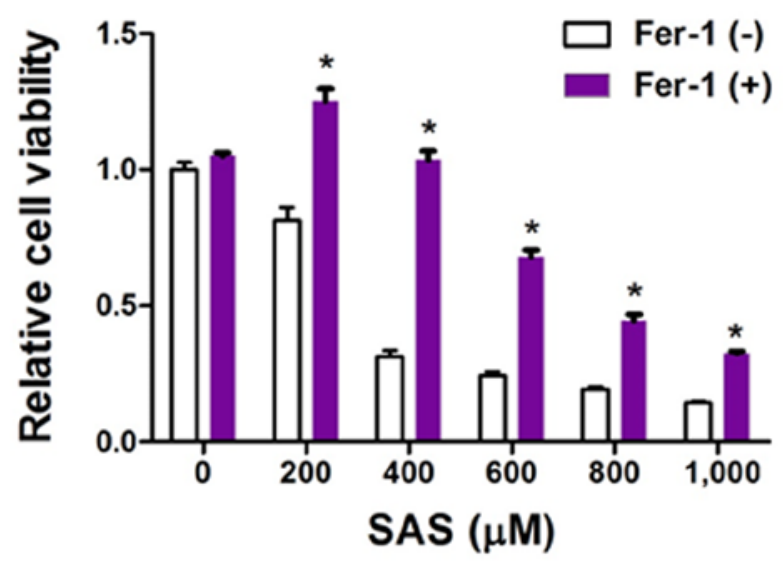

B

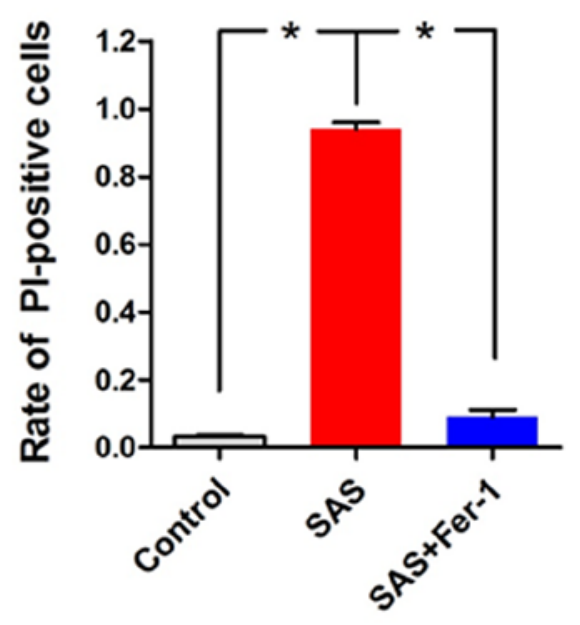

Control

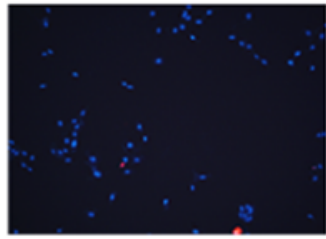

C

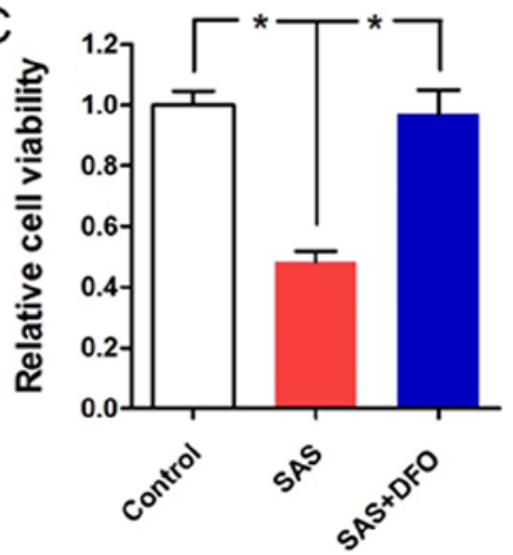

D

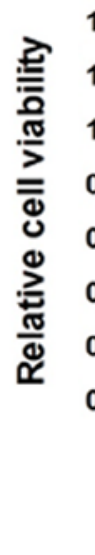

SAS $(200 \mu \mathrm{M})$

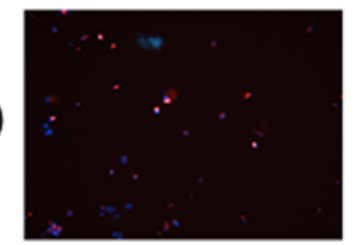

SAS $(200 \mu \mathrm{M})$

$+$

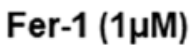

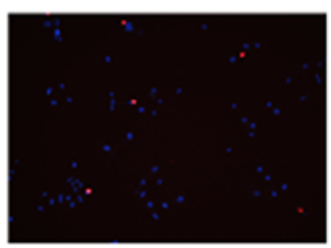

Figure 4. SAS induces cytotoxicity and cell death through ferroptosis in paclitaxel-resistant USC cells. (A) PTX1 cells were cultured for $1 \mathrm{~h}$ in the presence or absence of Fer-1 $(1 \mu \mathrm{M})$ and subsequently treated with different concentrations of SAS for $72 \mathrm{~h}$. Cell viability was assessed using the MTS assay. Cell viability was calculated from the ratio of the absorbance of cells treated with SAS or SAS + Fer-1 to that of untreated cells set as 1 (mean \pm SD; $n=8)$. (B) PTX1 cells were cultured for $1 \mathrm{~h}$ in the presence or absence of Fer-1 $(1 \mu \mathrm{M})$ and subsequently treated with or without SAS (200 $\mu \mathrm{M})$ for $24 \mathrm{~h}$. The cell death assay performed using PI and Hoechst nuclear staining. Left panel: Rate of PI-positive cells, right panel: Representative PI and Hoechst fluorescence images. (C) PTX1 cells were cultured for $1 \mathrm{~h}$ in the presence or absence of DFO $(1 \mu \mathrm{M})$ and subsequently treated with or without SAS (400 $\mu \mathrm{M})$ for $48 \mathrm{~h}$. Cell viability was assessed using the MTS assay. (D) PTX1 cells were cultured for $1 \mathrm{~h}$ in the presence or absence of Z-VAD-FMK (100 $\mu \mathrm{M})$ and subsequently treated with different concentrations of SAS for $72 \mathrm{~h}$. Cell viability was assessed using the MTS assay. Data are presented as the mean \pm SD. "P<0.05 vs. untreated cells. SAS, sulfasalazine; Fer-1, ferrostatin-1; PI, propidium iodide; DFO, deferoxamine; -, without; +, with.

suggest that activation of the JNK signaling pathway, which is downstream from Ras (35), enhances sensitivity to SAS in paclitaxel-resistant USC cells.
The effect of SAS on tumor growth inhibition. SAS has been widely demonstrated to inhibit tumor growth via xenograft animal models for human glioma, pancreatic and lung 
A

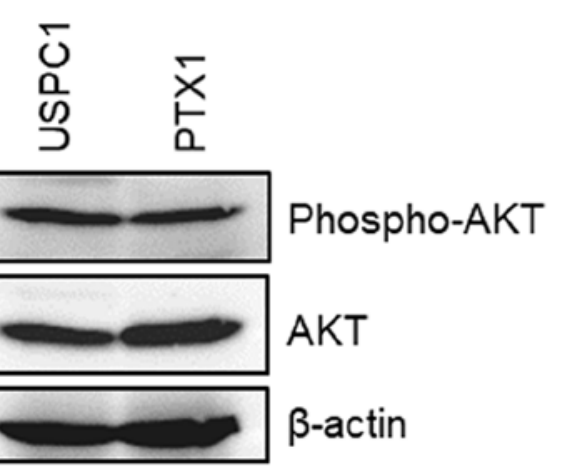

C
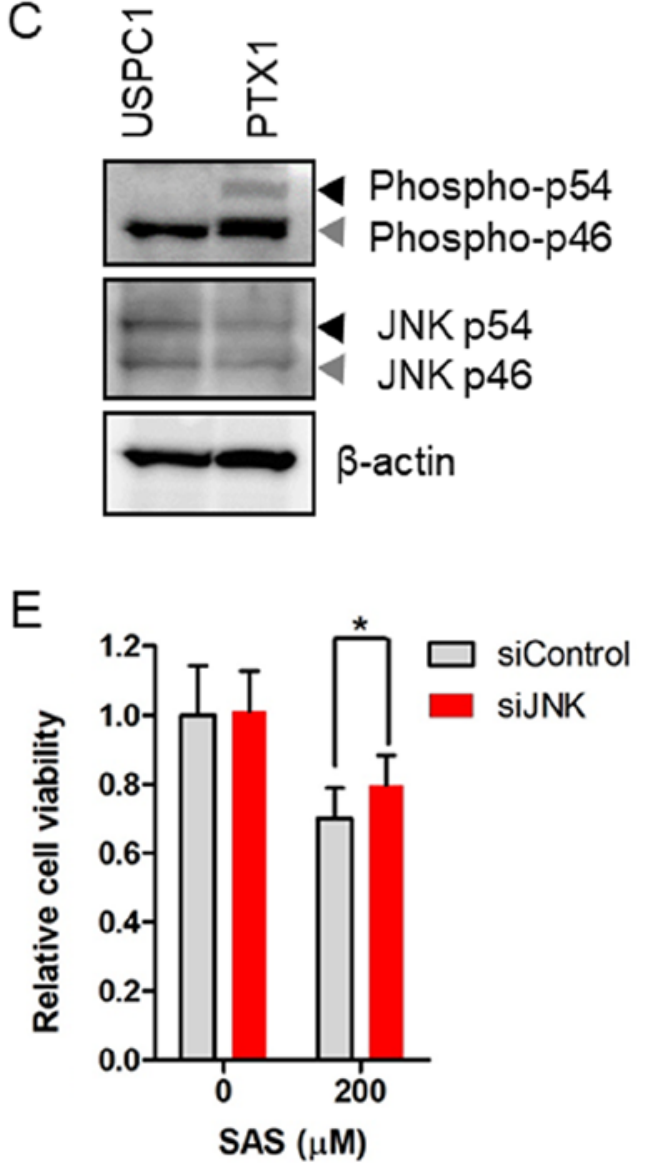

B

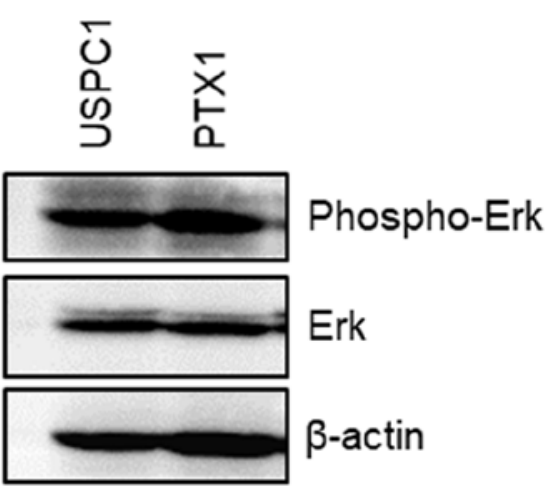

D

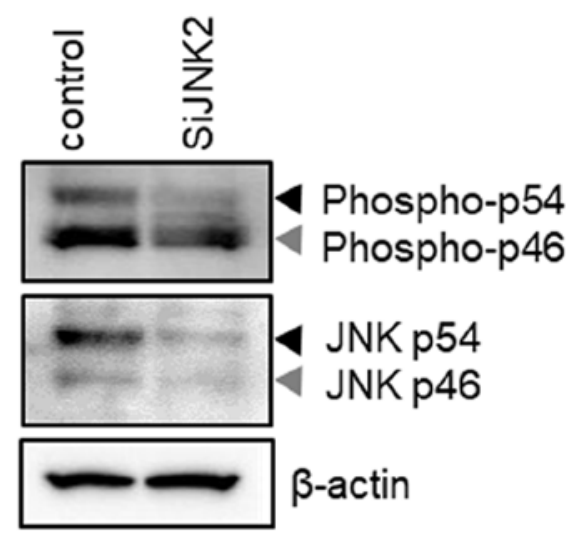

$\mathrm{F}$

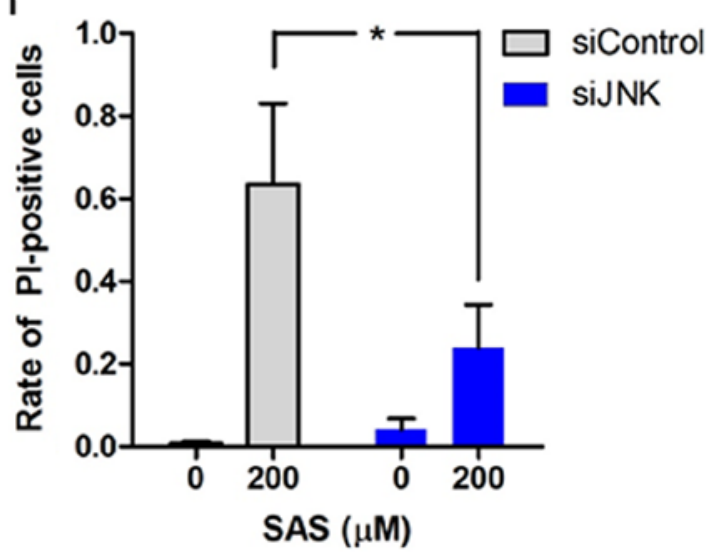

Figure 5. Expression and activation of Ras effectors in uterine serous carcinoma cells and the effect of JNK knockdown on SAS-induced cell-proliferation inhibition and cell death. Western blot analysis was performed to determine the expression levels of (A) AKT, (B) Erk and (C) JNK in USPC1 and PTX1 cells. $\beta$-actin was used as the internal control. Black arrows indicate JNK p54 isoform, while gray arrows indicate JNK p46 isoform. (D) PTX1 cells were transiently transfected with siRNAs against JNK or with a control siRNA and the cells were subjected to immunoblot analysis after 24 h. (E) PTX1 cells transfected control or JNK siRNAs were treated with $200 \mu \mathrm{M}$ SAS for $72 \mathrm{~h}$ and cell viability was assessed via the MTS assay. (F) PTX1 cells transfected with control or JNK siRNAs were treated with $200 \mu \mathrm{M}$ SAS for $24 \mathrm{~h}$ and the cell death assay was performed, using PI as a vital dye and Hoechst nuclear staining. Data are presented as the mean \pm SD. ${ }^{*} \mathrm{P}<0.05$ vs. control siRNA. SAS, sulfasalazine; si, small interfering; PI, propidium iodide.

cancer (36-38). The present study investigated whether SAS inhibited tumor growth in vivo using USPC1 cells. Two weeks after inoculation, one group of mice $(n=6)$ was administered with oral PBS, while a second group of mice $(n=6)$ was administered with SAS suspension $(250 \mathrm{mg} / \mathrm{kg})$. In the second group, two mice were excluded since one died of subcutaneous emphysema after SAS administration and the other exhibited no tumor formation due to failure of inoculation. Treatment with SAS had no significant effect on inhibiting tumor growth compared with the control treated with PBS (Fig. S2).

\section{Discussion}

The results of the present study demonstrated that the $\mathrm{xCT}$ inhibitor, SAS suppressed cell proliferation in the USC cell lines, and that the cytotoxic effect of SAS was stronger in paclitaxel-resistant cells compared with that in -sensitive cells. Furthermore, the results indicated that SAS-mediated cell death was induced through ferroptosis rather than apoptosis, in a JNK-dependent manner in paclitaxel-resistant cells. Collectively, these results suggest that $\mathrm{xCT}$ inhibition may 
be an effective treatment strategy for patients with recurrent paclitaxel-resistant USC.

Intracellular GSH levels were higher in paclitaxel-resistant USC cells compared with that in paclitaxel-sensitive cells. These results were consistent with previous findings, which suggest that high levels of GSH are observed in ovarian and prostate cancer and promote resistance to chemotherapy $(6,7)$. The $\mathrm{xc}^{-}$system, which is composed of $\mathrm{xCT}$ and $\mathrm{F} 42 \mathrm{hc}$, is essential for cystine uptake which is necessary for intracellular GSH synthesis, thus this system may also contribute to drug resistance in ovarian and lung cancer cells $(39,40)$. In the present study, the intracellular GSH levels were significantly higher in paclitaxel-resistant cells compared with those in paclitaxel-sensitive cells. However, the results of the present study exhibited no significant difference in $\mathrm{xCT}$ expression between paclitaxel-sensitive and -resistant cells. CD44v can enhance the capacity of GSH synthesis by stabilizing xCT (29); therefore, the difference in CD44v expression between paclitaxel-sensitive and -resistant cells was analyzed. Although GSH levels were significantly higher in PTX1 cells compared with those in USPC1 cells, CD44v was not expressed in PTX1 cells. These results suggested that CD44v was not associated with intracellular GSH levels in USC cells. Uptake of cystine by $\mathrm{xCT}$ provides the majority of cysteine into the cells, which is converted to GSH; however, a significant percentage is derived from methionine via the transsulfuration pathway (41). In a previous study, an xCT inhibitor depleted GSH levels to $51 \%$ of the control, while inhibition of the transsulfuration pathway depleted GSH to $77 \%$ of the control in glioma cells (41). Thus, intracellular GSH levels depend on the transsulfuration pathway in USC cells, along with xCT expression.

SAS has been extensively demonstrated to enhance the sensitivity of different types of cancer, such as colorectal, pancreatic, prostate and breast cancer, to chemotherapeutic agents by inducing GSH depletion, ROS accumulation and apoptosis (14,20-23). It was initially hypothesized that the xCT inhibitor, SAS, induced cytotoxicity and enhanced the efficacy of paclitaxel via inducing GSH depletion, ROS accumulation and apoptosis (14,20-23). The results of the present study demonstrated that SAS induced cytotoxicity; however, it did not enhance the efficacy of paclitaxel in USC cells. Combination treatment of paclitaxel with SAS had no marked effect on ROS accumulation compared with that in cells treated with SAS alone, thus, SAS did not enhance paclitaxel-induced cytotoxicity in both USC cell lines. Furthermore, SAS-mediated GSH depletion did not increase ROS accumulation and cell death in paclitaxel-sensitive USPC1 cells. The molecular mechanism underlying the association between GSH levels and ROS accumulation in USPC1 cells currently remains unclear and may involve additional antioxidants against ROS. SAS inhibits $\mathrm{xCT}$ and induces ferroptotic cell death in glioma cells (33), and head and neck cancer (42). The results of the present study demonstrated that SAS markedly induced GSH depletion and ROS accumulation, and promoted ferroptotic cell death in paclitaxel-resistant PTX1 cells. The use of a small-molecule activator of ferroptosis may enable selective elimination of cancer cells in which the Ras-RAF-MEK signaling pathway is activated, although this remains debated (43-45). Ras expression increases ROS production (46), and the interaction between ROS accumulation and Ras activation induces a synthetic lethality in cancer cells (47). The present study demonstrated that SAS increased ROS production in paclitaxel-resistant PTX1 cells, and that JNK, which is one of the downstream targets in the Ras signaling pathway (35), was activated in PTX1 cells, but not in paclitaxel-sensitive USPC1 cells. ROS accumulation and JNK activation may be essential for SAS-induced cytotoxicity and cell death, through ferroptosis in paclitaxel-resistant USC cells (Fig. S3). Previous studies have reported that JNK activation was associated with paclitaxel resistance in ovarian, pancreatic and lung cancer cells $(48,49)$. Taken together, these findings suggest that the synthetic lethal interaction between ROS accumulation and the activation of the Ras effector, JNK, induces ferroptotic cell death in paclitaxel-resistant USC cells, thus explaining why the cytotoxic effect of SAS was stronger in paclitaxel-resistant cells compared with that in -sensitive cells. Furthermore, ferroptosis may act as an endogenous tumor suppressive mechanism downstream of p53, which is stabilized and activated by JNK signaling (50), and therefore, SAS may readily induce ferroptosis in JNK-activated paclitaxel-resistant USC cells.

SAS has been widely found to inhibit tumor growth via xenograft animal models for human glioma, pancreatic and lung cancers (36-38). These reports demonstrate that the anticancer effects of SAS are based on the inhibition of NFKB, which is a transcription factor that plays a central role in the immune response and is involved in several physiological phenomena, such as acute and chronic inflammatory responses, cell proliferation and apoptosis (51). The present study demonstrated that SAS had no significant effect on inhibiting tumor growth compared with the control in paclitaxel-sensitive cells. The in vitro analysis demonstrated that SAS promoted cytotoxicity more effectively in paclitaxel-resistant cells than -sensitive cells. If paclitaxel-resistant PTX-1 cells exhibited tumorigenic activity and SAS demonstrated inhibition of tumor growth in mice studies, SAS may have been considered a strong candidate target in the treatment of patients with paclitaxel-resistant USC. A major limitation of the present study was that all experiments were performed with only one paclitaxel-resistant USC cell line. Thus, prospective studies will focus on using different cell lines, to confirm the effect of SAS on USC cells.

The $\mathrm{xCT}$ inhibitor, SAS is clinically used in treating bowel disease and rheumatoid arthritis (15). However, there has been limited positive response to xCT-targeted therapy in cancer. A phase I/II study investigating SAS in patients $(n=10)$ with recurrent or progressive glioma was terminated due to a lack of clinical response and the high frequency of grade 1-2 adverse effects, including increased neurologic deficit, neutropenia, thrombocytopenia, proteinuria (52). Similar results were reported in patients with advanced and chemotherapy-resistant gastric cancer $(53,54)$. In these clinical studies, patients continuously received SAS orally between 1.5 and $6 \mathrm{~g} /$ day, and the results from the present study demonstrated that SAS inhibited $\mathrm{xCT}$ at a dose of $200 \mu \mathrm{M}$ in paclitaxel-resistant USC cell lines. A total of $200 \mu \mathrm{M} \mathrm{SAS}$ is equivalent to a SAS dose of $5.6 \mathrm{~g} / \mathrm{day}$, and this dose was $\sim 1.6$ folds higher compared with that routinely used to treat Crohn's disease (55). Thus, the use of SAS as a novel candidate for recurrent USC chemotherapy-resistant treatment may be questionable, and the development of more potent $\mathrm{xCT}$ inhibitors are required for the clinical treatment of patients with recurrent USC. 
xCT inhibition induces cell death in cancer stem cells (29), and normalizes the tumor microenvironment by decreasing tumor-derived edema in glioma (32). Thus, targeting xCT inhibition may be used to maintain therapy for patients with recurrent chemotherapy-resistant USC.

In summary, the effect of the $\mathrm{xCT}$ inhibitor, SAS on cytotoxicity was stronger in paclitaxel-resistant USC cells compared with that in paclitaxel-sensitive USC cells. Furthermore, the synthetic lethal interaction between the accumulation of ROS and the activation of the Ras effector, JNK, induced cell-proliferation inhibition and ferroptotic cell death in paclitaxel-resistant USC cells. However, previous studies on SAS have reported a lack of clinical response and frequent adverse effects. Thus, the development of more potent xCT inhibitors are required for clinical application. Collectively, the results of the present study suggest that $\mathrm{xCT}$ inhibition may be an effective treatment for patients with recurrent paclitaxel-resistant USC.

\section{Acknowledgements}

The authors would like to thank Ms Chisato Tateishi (Experimental Research Technician, Department of Obstetrics and Gynecology, Faculty of Medicine, Yamagata University, Yamagata, Japan) for technical assistance.

\section{Funding}

The present study was funded in part by the Japan Society for the Promotion of Scientific KAKENHI (grant nos. 15K10699 and 17K16827).

\section{Availability of data and materials}

The datasets used and/or analyzed during the present study are available from the corresponding author on reasonable request.

\section{Authors' contributions}

AS, TO and SN designed the study. AS, MS and KT conducted the experiments. AS, TO and MO analyzed the data. AS and TO wrote the main manuscript and prepared all figures. All authors interpreted the results. All authors reviewed and approved the final manuscript.

\section{Ethics approval and consent to participate}

The procedures involving animals used in the present study were approved by the Animal Care Committee of Yamagata University (approval no. 31009) in accordance with institutional and Japanese government guidelines for animal experiments.

\section{Patient consent for publication}

Not applicable.

\section{Competing interests}

S. Nagase received lecture fees from Chugai Pharmacetical Co. Ltd., and AstraZeneca.

\section{References}

1. Menderes G, Clark M and Santin AD: Novel targeted therapies in uterine serous carcinoma, an aggressive variant of endometrial cancer. Discov Med 21: 293-303, 2016.

2. Hamilton CA, Cheung MK, Osann K, Chen L, Teng NN Longacre TA, Powell MA, Hendrickson MR, Kapp DS and Chan JK: Uterine papillary serous and clear cell carcinomas predict for poorer survival compared to grade 3 endometrioid corpus cancers. Br J Cancer 94: 642-646, 2006.

3. Boruta DM II, Gehrig PA, Fader AN and Olawaiye AB: Management of women withuterine papillary serous cancer: A society of gynecologic oncology (SGO) review. Gynecol Oncol 115: 142-153, 2009.

4. Goff BA, Kato D, Schmidt RA, Ek M, Ferry JA, Munts HG, Cain JM, Tamimi HK, Figge DC and Greer BE: Uterine papillary serous carcinoma: Patterns of metastatic spread. Gynecol Oncol 54: 264-268, 1994.

5. Lecane PS, Karaman MW, Sirisawad M, Naumovski L, Miller RA, Hacia JG and Magda D: Motexafin gadolinium and zinc induce oxidative stress responses and apoptosis in B-cell lymphoma lines. Cancer Res 65: 11676-11688, 2005.

6. Godwin AK, Meister A, O'Dwyer PJ, Huang CS, Hamilton TC and Anderson ME: High resistance to cisplatin in human ovarian cancer cell lines is associated with marked increase of glutathione synthesis. Proc Natl Acad Sci USA 89: 3070-3074, 1992.

7. Mulcahy RT, Untawale S and Gipp JJ: Transcriptional up-regulation of gamma-glutamylcysteine synthetase gene expression in melphalan-resistant human prostate carcinoma cells. Mol Pharmacol 46: 909-914, 1994.

8. Trachootham D, Alexandre J and Huang P: Targeting cancer cells by ROS-mediated mechanisms: A radical therapeutic approach? Nat Rev Drug Discov 8: 579-591, 2009.

9. Seino M, Ohta T, Sugiyama A, Sakaki H, Sudo T, Tsutsumi S, Shigeta S, Tokunaga H, Toyoshima M, Yaegashi N and Nagase S: Metabolomic analysis of uterine serous carcinoma with acquired resistance to paclitaxel. Oncotarget 9: 31985-31998, 2018.

10. Lo M, Wang Y and Gout PW: The $\mathrm{x}(\mathrm{c})$ - cystine/glutamate antiporter: A potential target for therapy of cancer and other diseases. J Cell Physiol 215: 593-602, 2008.

11. Aquilano K, Baldelli S and Ciriolo MR: Glutathione: New roles in redox signaling for an old antioxidant. Front Pharmacol 5: 196, 2014.

12. Yoshikawa M, Tsuchihashi K, Ishimoto T, Yae T, Motohara T, Sugihara E, Onishi N, Masuko T, Yoshizawa K, Kawashiri S, et al: $\mathrm{xCT}$ inhibition depletes CD44v-expressing tumor cells that are resistant to EGFR-targeted therapy in head and neck squamous cell carcinoma. Cancer Res 73: 1855-1866, 2013.

13. Wu WJ, Zhang Y, Zeng ZL, Li XB, Hu KS, Luo HY, Yang J, Huang $\mathrm{P}$ and $\mathrm{Xu} \mathrm{RH}$ : $\beta$-phenylethyl isothiocyanate reverses platinum resistance by a GSH-dependent mechanism in cancer cells with epithelial-mesenchymal transition phenotype. Biochem Pharmacol 85: 486-496, 2013.

14. Ma MZ, Chen G, Wang P, Lu WH, Zhu CF, Song M, Yang J, Wen S, Xu RH, Hu Y and Huang P: Xc- inhibitor sulfasalazine sensitizes colorectal cancer to cisplatin by a GSH-dependent mechanism. Cancer Lett 368: 88-96, 2015.

15. Zenlea $T$ and Peppercorn MA: Immunosuppressive therapies for inflammatory bowel disease 20: 3146-3152, 2014

16. Zhang W, Trachootham D, Liu J, Chen G, Pelicano $\mathrm{H}$, Garcia-Prieto C, Lu W, Burger JA, Croce CM, Plunkett W, et al: Stromal control of cystine metabolism promotes cancer cell survival in chronic lymphocytic leukaemia. Nat Cell Biol 14: 276-286, 2012.

17. Podolsky DK: Inflammatory bowel disease. N Engl J Med 347: 417-429, 2002.

18. Nielsen $\mathrm{OH}$, Verspaget $\mathrm{HW}$ and Elmgreen J: Inhibition of intestinal macrophage chemotaxis to leukotriene B4 by sulphasalazine, olsalazine, and 5-aminosalicylic acid. Aliment Pharmacol Ther 2: 203-211, 1988.

19. Wahl C, Liptay S, Adler G and Schmid RM: Sulfasalazine: A potent and specific inhibitor of nuclear factor kappa B. J Clin Invest 101: 1163-1174, 1998

20. Lo M, Ling V, Low C, Wang YZ and Gout PW: Potential use of the anti-inflammatory drug, sulfasalazine, for targeted therapy of pancreatic cancer. Curr Oncol 17: 9-16, 2010.

21. Doxsee DW, Gout PW, Kurita T, Lo M, Buckley AR, Wang Y, Xue H, Karp CM, Cutz JC, Cunha GR and Wang YZ: Sulfasalazine-induced cystine starvation: Potential use for prostate cancer therapy. Prostate 67: 162-171, 2007. 
22. Nnrang VS, Pauletti GM, Gout PW, Buckley DJ and Buckley AR: Sulfasalazine-induced reduction of glutathione levels in breast cancer cells: Enhancement of growth-inhibitory activity of Doxorubicin. Chemotherapy 53: 210-217, 2007.

23. Kagami T, Wang Y, Tien A, Watahiki A, Lo M, Xue H, Gout P and Wang ZY: Sulfasalazine enhances growth-inhibitory activity of doxorubicin: Potential use in combination therapy of advanced prostate cancer. Proc 98th Ann Assoc Cancer Res (Ros Angeles, CA), 2007.

24. Dixon SJ, Lemberg KM, Lamprecht MR, Skouta R, Zaitsev EM, Gleason CE, Patel DN, Bauer AJ, Cantley AM, Yang WS, et al: Ferroptosis: An iron-dependent form of nonapoptotic cell death. Cell 149: 1060-1072, 2012.

25. Cao JY and Dixon SJ: Mechanisms of ferroptosis. Cell Mol Life Sci 73: 2195-2209, 2016.

26. Santin AD, Bellone S, Gokden M, Palmieri M, Dunn D, Agha J, Roman JJ, Hutchins L, Pecorelli S, O'Brien T, et al: Overexpression of HER-2/neu in uterine serous papillary cancer. Clin Cancer Res 8: 1271-1279, 2002.

27. Sakaki H, Okada M, Kuramoto K, Takeda H, Watarai H, Suzuki S, Seino S, Seino M, Ohta T, Nagase S, et al: GSKJ4, a selective Jumonji H3K27 demethylase inhibitor, effectively targets ovarian cancer stem cells. Anticancer Res 35: 6607-6614, 2015.

28. Orian-Rousseau V: CD44 acts as a signaling platform controlling tumor progression and metastasis. Front Immunol 6: 154, 2015.

29. Tanabe KK, Nishi T and Saya H: Novel variants of CD44 arising from alternative splicing: Changes in the CD44 alternative splicing pattern of MCF-7 breast carcinoma cells treated with hyaluronidase. Mol Carcinog 7: 212-220, 1993.

30. Ishimoto T, Nagano O, Yae T, Tamada M, Motohara T, Oshima H, Oshima M, Ikeda T, Asaba R, Yagi H, et al: CD44 variant regulates redox status in cancer cells by stabilizing the $\mathrm{xCT}$ subunit of system $\mathrm{xc}(-)$ and thereby promotes tumor growth. Cancer Cell 19: 387-400, 2011

31. Yae T, Tsuchihashi K, Ishimoto T, Motohara T, Yoshikawa M, Yoshida GJ, Wada T, Masuko T, Mogushi K, Tanaka H, et al: Alternative splicing of CD44 mRNA by ESRP1 enhances lung colonization of metastatic cancer cell. Nat Commun 3: 883, 2012.

32. Oliver FJ, de la Rubia G, Rolli V, Ruiz-Ruiz MC, de Murcia G and Murcia JM: Importance of poly(ADP-ribose) polymerase and its cleavage in apoptosis. Lesson from an uncleavable mutant. J Biol Chem 273: 33533-33539, 1998.

33. Shem T, Fan Z, Ghoochani A, Rauh M, Engelhorn $T$, Minakaki G, Dörfler A, Klucken J, Buchfelder M, Eyüpoglu IY and Savaskan N: Sulfasalazine impacts on ferroptotic cell death and alleviates the tumor microenvironment and glioma-induced brain edema. Oncotarget 7: 36021-36033, 2016.

34. Misaghi S, Korbel GA, Kessler B, Spooner E and Ploegh HL: z-VAD-fmk inhibits peptide:N-glycanase and may result in ER stress. Cell Death Differ 13: 163-165, 2006.

35. Enomoto M, Kizawa D, Ohsawa S and Igaki T: JNK signaling is converted from anti- to pro-tumor pathway by Ras-mediated switch of Warts activity. Dev Biol 403: 162-171, 2015.

36. Robe PA, Bentires-Alj M, Bonif M, Rogister B, Deprez M, Haddada H, Khac MT, Jolois O, Erkmen K, Merville MP, et al: In vitro and in vivo activity of the nuclear factor-kappaB inhibitor sulfasalazine in human glioblastomas. Clin Cancer Res 10 5595-5603, 2004.

37. Müerköster S, Arlt A, Witt M, Gehrz A, Haye S, March C, Grohmann F, Wegehenkel K, Kalthoff H, Fölsch UR and Schäfer H: Usage of the NF-kappaB inhibitor sulfasalazine as sensitizing agent in combined chemotherapy of pancreatic cancer. Int J Cancer 104: 469-476, 2003.

38. Lay JD, Hong CC, Huang JS, Yang YY, Pao CY, Liu CH, Lai YP, Lai GM, Cheng AL, Su IJ and Chuang SE: Sulfasalazine suppresses drug resistance and invasiveness of lung adenocarcinoma cells expressing AXL. Cancer Res 67: 3878-3887, 2007.

39. Okuno S, Sato H, Kuriyama-Matsumura K, Tamba M, Wang H, Sohda S, Hamada H, Yoshikawa H, Kondo T and Bannai S: Role of cystine transport in intracellular glutathione level and cisplatin resistance in human ovarian cancer cell lines. Br J Cancer 88 951-956, 2003
40. Huang Y, Dai Z, Barbacioru C and Sadée W: Cystine-glutamate transporter SLC7A11 in cancer chemosensitivity and chemoresistance. Cancer Res 65: 7446-7456, 2005.

41. Kandil S, Brennan L and McBean GJ: Glutathione depletion causes a JNK and p38MAPK-mediated increase in expression of cystathionine-gamma-lyase and upregulation of the transsulfuration pathway in C6 glioma cells. Neurochem Int 56: 611-619, 2010.

42. Roh JL, Kim EH, Jang HJ, Park JY and Shin D: Induction of ferroptotic cell death for overcoming cisplatin resistance of head and neck cancer. Cancer Lett 381: 96-103, 2016.

43. Yang WS, SriRamaratnam R, Welsch ME, Shimada K, Skouta R, Viswanathan VS, Cheah JH, Clemons PA, Shamji AF, Clish CB, et al: Regulation of ferroptotic cancer cell death by GPX4. Cell 156: 317-331, 2014

44. Dolma S, Lessnick SL, Hahn WC and Stockwell BR: Identification of genotype-selective antitumor agents using synthetic lethal chemical screening in engineered human tumor cells. Cancer Cell 3: 285-296, 2003.

45. Yagoda N, von Rechenberg M, Zaganjor E, Bauer AJ, Yang WS, Fridman DJ, Wolpaw AJ, Smukste I, Peltier JM, Boniface JJ, et al: RAS-RAF-MEK-dependent oxidative cell death involving voltage-dependent anion channels. Nature 447: 864-868, 2007.

46. Irani K, Xia Y, Zweier JL, Sollott SJ, Der CJ, Fearon ER, Sundaresan M, Finkel $\mathrm{T}$ and Goldschmidt-Clermont PJ: Mitogenic signaling mediated by oxidants in Ras-transformed fibroblasts. Science 275: 1649-1652, 1997.

47. Garama DJ, Harris TJ, White CL, Rossello FJ, Abdul-Hay M, Gough DJ and Levy DE: A synthetic lethal interaction between glutathione synthesis and mitochondrial reactive oxygen species provides a tumor-specific vulnerability dependent on STAT3. Mol Cell Biol 35: 3646-3656, 2015.

48. Seino M, Okada M, Sakaki H, Takeda H, Watarai H, Suzuki S, Seino S, Kuramoto K, Ohta T, Nagase S, et al: Time-staggered inhibition of JNK effectively sensitizes chemoresistant ovarian cancer cells to cisplatin and paclitaxel. Oncol Rep 35: 593-601, 2016.

49. Okada M, Kuramoto K, Takeda H, Watarai H, Sakaki H, Seino S, Seino M, Suzuki S and Kitanaka C: The novel JNK inhibitor AS602801 inhibits cancer stem cells in vitro and in vivo. Oncotarget 7: 27021-27032, 2016.

50. Jiang L, Kon N, Li T, Wang SJ, Su T, Hibshoosh H, Baer R and $\mathrm{Gu}$ W: Ferroptosis as a p53-mediated activity during tumour suppression. Nature 520: 57-62, 2015.

51. Gilmore TD: Introduction to NF-kappaB: Players, pathways, perspectives. Oncogene 25: 6680-6684, 2006.

52. Robe PA, Martin DH, Nguyen-Khac MT, Artesi M, Deprez M, Albert A, Vanbelle S, Califice S, Bredel M and Bours V: Early termination of ISRCTN45828668, a phase $1 / 2$ prospective, randomized study of sulfasalazine for the treatment of progressing malignant gliomas in adults. BMC Cancer 9: 372, 2009.

53. Shitara K, Doi T, Nagano O, Imamura CK, Ozeki T, Ishii Y, Tsuchihashi K, Takahashi S, Nakajima TE, Hironaka S, et al: Dose-escalation study for the targeting of CD44v+ cancer stem cells by sulfasalazine in patients with advanced gastric cancer (EPOC1205). Gastric Cancer 20: 341-349, 2017.

54. Shitara K, Doi T, Nagano O, Fukutani M, Hasegawa H, Nomura S, Sato A, Kuwata T, Asai K, Einaga Y, et al: Phase 1 study of sulfasalazine and cisplatin for patients with CD44v-positive gastric cancer refractory to cisplatin (EPOC1407). Gastric Cancer 20: 1004-1009, 2017.

55. Sandborn WJ and Feagan BG: Review article: Mild to moderate Crohn's disease-defining the basis for a new treatment algorithm. Aliment Pharmacol Ther 18: 263-277, 2003.

This work is licensed under a Creative Commons Attribution-NonCommercial-NoDerivatives 4.0 International (CC BY-NC-ND 4.0) License. 